\title{
AN OVERVIEW FOR QUALITY EVALUATION IN PRODUCTION AND SERVICE SECTORS: AN APPLICATION IN MANUFACTURING SECTOR
}

DOI: 10.17261/Pressacademia.2018.875

PAP- V.7-2018(28)-p.170-175

\section{Aysenur Erdil' ${ }^{1}$, Ahmet Ekerim ${ }^{2}$}

${ }^{1}$ Marmara-Anadolu University, Istanbul, Turkey.

erdil.aysenur@gmail.com, ORCID: 0000-0002-6413-7482

${ }^{2}$ Yildiz Technical University, Istanbul, Turkey.

ahmetekerim@gmail.com, ORCID: 0000-0003-3858-1077

To cite this document

Erdil, A., Ekerim, A. (2018). An overview for quality evaluation in production and service sectors: an application in manufacturing sector. PressAcademia Procedia (PAP), V.7, p.170-175.

Permemant link to this document: $h$ ttp://doi.org/10.17261/Pressacademia.2018.875

Copyright: Published by PressAcademia and limited licenced re-use rights only.

\begin{abstract}
Purpose- Within the scope of the main objective of this study, poka-yoke application and FMEA applications-previous studies in the literature aiming to search a simple yet effective solution that increase effectiveness and efficiency in the companies were mentioned Methodology- FMEA, a more practical, flexible and reliable method for preventing risks at every stage of the service or manufacturing sector, has been used in this study. FMEA study-application was implemented-conducted for a door hinge component produced by a refrigerator hardware materials manufacturer.

Findings- In the analysis of the study, the steps of FMEA have been tried to be implemented at the stages of production design, service and process. It was observed that the (RPN) values of the possible faults detected in the system before the HTEA Analysis process were high Conclusion- FMEA is a method which reduces the risks of strategic goals and eliminates them from the system, could be used in quality management and literature studies relating this issue were included in the content of this research. According to the HTEA, the measure taken for each failure resulting from the analysis and the second Risk analysis for the failure due to the actions of the countermeasures showed that the RPN values of the failure with high-risk value were lowered.
\end{abstract}

Keywords: Quality control, failure modes and effect analysis, risk priority number. JEL Codes: L15, G81, D32, Q50

\section{ÜRETIM VE HIZMET SEKTÖRÜNDE KALITE DEĞERLENDIRILMESINE GENEL BAKIŞ: ÜRETiM SEKTÖRÜNDE HATA TÜRLERI VE ETKI ANALIZ UYGULAMASI}

\section{ÖZET}

Amaç- Bu çalışmanın temel amacı kapsamında, İşletmeler bünyesinde etkinliği ve verimliliği arttıracak, basit ancak etkili şekilde çözüm bulmayı amaçlayan HTEA uygulamasına değinilmiştir. Bir buzdolabı donanım malzemeleri üretici firma tarafından üretilen kapı menteşe bileşenine yönelik Hata türü ve etkileri analizi çalışması yapıldı.

Yöntem- Hizmet ya da üretim sektörlerünün her aşamasında risklerin önlenmesine yönelik daha pratik, esnek ve güvenilir yöntem olan HTEA bu çalışma kapsamında kullanılmıştır. Bu süreç kapsamında yapılmış örnek HTEA çalışmalarında ve bu çalışma kapsamdaki uygulamada bulunarak gözlemlenmiştir.

Bulgular- Çalışma sonucunda bir dönemlik iyileşme yüzdesinin teorik olarak $\% 35,23$; fiili olarak $\% 33,15$ olarak gerçekleştiği görülmüştür. İyileştirme için ayrılacak imkânlar sınırlı olduğu için tüm riskler bir dönem içersinde düşürülmeyebilir

Sonuç- Tespit edilen hataların değerlerine bağlı olarak Risk Öncelikli Katsayısı (RÖS-RPN) hesaplandı. Bu hesaplanan değerler risk büyüklüğüne göre sıralanıp, RÖS değerinin azaltılmasına yönelik çalışmalarda bulunuldu. HTEA tablosunda getirilen çözüm önerilerine göre hareket edilerek risk oranlarının düştüğü gözlemlendi. Maliyetlerin azaldığı ve kalite düzeyi yükseldi.

Anahtar Kelimeler: Kalite kontrol, hata türleri ve etki analizi, risk öncelik göstergesi, sürdürülebilirlik. JEL Kodları: L15, G81, D32, Q50 


\section{Giriş}

HTEA ile elde edilen bilgiler tasarımda, üretim sürecinde değişiklikler yapma, kullanılan malzemeyi değiştirme, kalite kontrol ve kalite muayene ölçütlerini tekrar gözden geçirme gibi kararların verilmesinde kullanıldığından, yöntem karar verme aracı olarak da değerlendirilir. HTEA (Hata Türü ve Etkileri Analizi), meydana gelebilecek hataları önceden tahmin ederek önlemeye yönelik güçlü bir teknik olarak bilinir. HTEA, hataların ortaya çıkmasıyla meydana gelebilecek problemlerin son kullanıcıya (müşteriye) olan etkilerini, kullanıcı (müşteri) gözüyle analiz etme prensibine dayanır (Dizdar, 2000; Dizdar ve Kurt, 2002; Eleran, 2004).

Belirtilen mühendislik avantajlarının yanında ayrıca Hata Türleri ve Etkileri Analizi tekniği kullanmanın getirdiği genel anlamdaki avantajlar şu şekilde sıralanabilir (Hough, 2000):

-Şirket imajını arttırır. En uygun sistem tasarımını seçmekte kolaylık sağlar.

-Ürün geliştirme zaman ve maliyetini azaltır.

-Hizmet veya ürünlerin kalitesini ve güvenilirliğini arttırır.

-Rekabet avantajını arttırır. Müşteri tatminini arttırır.

-Tasarım geliştirme faaliyetlerinde bir öncelik sağlar. Organizasyon kültürünü arttırır.

HTEA çalışmaları (Elliott, 1998); Hataları önleyebilecek programlar, planlar hazırlanır. Bakım, operasyon ve kontrol talimatlarında yapılabilcek değişiklikler belirlenir. Tasarım ve özelliklere yönelik ne gibi değişiklikler yapılabileceği, gereksinim duyulan bakım süresi, gerekli duyulan bakım araç-gereci temin etme ve ihtiyaç duyulan testler belirlenir (Elliott, 1998).

\section{LITERATÜR ARAŞTIRMASI}

\subsection{Hata Türü ve Etki Analizi'nin Kalite Sistemi İçindeki Yeri}

Günümüzde çalışmaların son zamanlarda yaygınlaşan bulanık mantık, çok kriterli karar verme, yapay sinir ağları, simulasyon, vb. yöntemlerle birlikte yapıldığı görülmektedir (Şen, 2001). HTEA analizinin önemli bir parçası olan risk öncelik göstergesinin hesaplanması ve ona göre risk faktörlerinin sıralanması aşamasında çok kriterli karar verme yöntemlerinden Analitik Hiyerarşi Süreci veya Fuzzy TOPSıS yöntemlerinin kullanılması örnek olarak verilebilir (Eleran ve digerleri, 2004; ; Hough, 2000; Klir ve Yuan, 1995; Şen, 2001; Wang, 1997).

Kasa ve Boran (1993), kendi çalışmaları kapsamında FMEA tekniğinin Toplam Kalite Yönetimindeki yerine yönelik araştırmalarda bulundular. Çalışmanın sonuç kısmında, hatanın oluşma nedenlerine girerek ve bu konuların irdelenmesiyle önlenmesine yönelik çözümler üretilmeye gidilmiştir. Kusursuzluğu hedeflemenin en akılcı ve pratik çözüm olduğu belirlenmiştir. Bolat (2000), çalışmasında HTEA tekniğinin faydaları, avantajları üzerinde durmuştur. İvmelendirici mıknatıslar üzerindeki uygulamaları ise Bellomo ve diğerleri (2000) tarafından yapılmıştır. Yılmaz (2000), Hata Türü Ve Etki Analizi başlıklı çalışmasında; bu tekniğin turizm sektörüne de uygulanabileceği ve sonucunda; turistik işletmelerin müşteri tatminini sağlamasının kolaylaşacağı, maliyetlerinin düşeceği, rekabet gücünün artacağı ve imajının güçleneceğini ortaya çıkarmıştır. Düzgüner (2002), yaptığı çalışma kapsamında HTEA'ni ürün geliştirme sürecinde önleyici kalite güvence tekniği olarak ele almıştır. Çalışma kapsamında ABC Beyaz Eşya San. Ve Tic. A.Ş.'de Tasarım HTEA için kontrol listeleri oluşturularak, tekniğin müşteri memnuniyetine katkısı gözlenmiştir. Scipioni ve diğerleri (2002), çalışmasında HTEA Formu örneği oluşturmuştur. Pillay ve Wang (2002), genel bir HTEA formunun nasıl olacağına yönelik prosedür geliştirmiştir. Eryürek ve Tanyaş (2003), HTEA analizi tekniği sayesinde maliyet odaklı karar verme yaklaşımı üzerinde çalışmada bulunmuşlardır. Hatanın etkisini, büyüklüğünü ve maliyetini birlikte değerlendiren bir uygulama çalışması sonucunda, klasik HTEA tekniği kapsamında hatanın önlenmesi yönünde boyutu kuvvetlendirilmiş, karar verme aşaması daha objektif hale getirilip maliyet kriteri eklenmiş, karar verme konusunda sisteme bütünsel bakım sayesinde yöntem daha etkin sonuç vermiştir.

Engin ve Kaya (2004), trafik kazalarının önlenmesine yönelik Hata Modu Ve Etkileri Analizi (HTEA) modeli ile ilgili bir çalışmada bulunmuşlar. Çalışmanın sonucunda HTEA tekniği kullanarak trafik kazası oranının düştüğü görülmüştür. Hata Türü ve Etki Analizi, riskleri tahmin ederek hataları önlemeye yönelik güçlü bir analiz tekniğidir. Hatanın ortaya çıkması ile doğacak problemin müşteri tarafından algılanması prensibine dayanmaktadır. Hata Türü ve etki Analizi çalışmasında belirlenen bütün hatalar için olasılık, şiddet ve saptanabilirlik tahmini yapılmaktadır (Milli Prodüktivite Merkezi Yayınları, 1998; Efil, 2004). HTEA yoluyla risklerin, kritik etkilerini ve aralarındaki bağımlılıkları daha iyi anlamaları konusunda işletmelere yardımcı olabilir. Bu nedenle, Kalite Fonksiyonlarıdan HTEA teknikleri kapsamında karar verme süreçlerinin iyileştirme, geliştirme yönüne ve riskleri azaltma yeteneğine sahiptir (Besterfield, 1999; Bilgin, 1994; Saajedi, 2004; Vilko ve Hallikas, 2012; Wang, 2004). Hata Türü ve Etkileri Analizi tekniği belirtilen bir akış içerisinde çeşitliliğe sahiptir ve uygulama aşamasında her türlü üretim ve hizmet şeklini içermektedir (Tamer, 2000; Wang ve digerleri, 2012).

\section{VERI VE YÖNTEM}

Bir buzdolabı donanım malzemeleri üretici firma ( $A B C$ beyaz eşya şirketi) tarafından üretilen kapı menteşe bileşen malzemesine yönelik hata türü ve etkileri analizi çalışması yapıldı. Bu çalışma kapsamında HTEA analiz akışındaki süreç takip edildi. Süreç sonrası hata önlenerek müşteriyi memnun edici unsur sağlanıp, hedeflenen amaç ve sonuca ulaşıldı. Bu çalışma kapsamında, Buz dolabı kapısındaki kablosuna ait ürün fonksiyon özelliğine incelendiğinde, $A B C$ firmasının ürettiği xyz-frost isimli buzdolabı kapısının üstündeki elektronik yapı ile gövdesinde bulunan elektronik kontrol düzeneği arasında bilgi iletimine imkan sağlayan ara bileşen-elemendır. Müşterinin ihtiyaç ve beklentisine bağlı olarak kapının her iki yönden açılıp-kapanması istenebileceğinden her kapıya iki adet takılır. 
Ürün bileşenin ait HTEA analizini gerçekleştirme sürecinde Risk Öncelikli Katsayısının (RÖS) belirlenmesi yönünde ürün bileşenine ait tespit edilen özel hatalara yönelik şiddetderecelendirilmesi (Tablo 1), hatanın-sorunun ortaya çıkma olasılığını (Tablo 2) ve hatanın-sorunun saptanabilirliğini - keşfedilebilirliğini (Tablo 3) gösteren tablolar oluşturuldu.

Tablo 1: Buzdolabı Bileşenine Ait Hata Şiddeti Derecelendirme Tablosu

\begin{tabular}{|c|c|}
\hline 1 & $\begin{array}{l}\text { Müşterinin ürünü kullanımı aşamasında, performans konusunda herhangi bir eksiklik ve sorun } \\
\text { oluşturmayacak. Müşteri tarafından bu eksiklik görülmiyecek, hissedilmiyecek. }\end{array}$ \\
\hline 2 & \multirow{2}{*}{ Şiddet derecesi düşük, müşteri tarafından bu hatayı görülmeyecek ya da gözardı edilecek. } \\
\hline 3 & \\
\hline 4 & \multirow{3}{*}{$\begin{array}{l}\text { Olumsuz etkiyi performans düzeyinde orta seviyede oluşturacak, müşteri üzerinde kısmen } \\
\text { memnuniyetsizlik oluşturacak. }\end{array}$} \\
\hline 5 & \\
\hline 6 & \\
\hline 7 & \multirow{2}{*}{$\begin{array}{l}\text { Performansı ileri seviyede performas üzerinde etkisini gösterecek, müşteride büyük ihtimalle } \\
\text { tatminsizlik-hoşnutsuzluk oluşturacak. Ürün iade durumu olacak. }\end{array}$} \\
\hline 8 & \\
\hline 9 & \multirow{2}{*}{$\begin{array}{l}\text { Müşteri memnuniyetsizliği yüksek seviyede oluşacak, ürün iadesi gerçekleşecek ve büyük ihtimalle } \\
\text { müşteri yaşanan olaya bağlı tazminat talep edecektir. }\end{array}$} \\
\hline 10 & \\
\hline
\end{tabular}

\section{Tablo 2: Buzdolabı Bileşenine Ait Hata Olasılık Derecelendirme Tablosu}

\begin{tabular}{|c|c|}
\hline 1 & Oluşma olasılığı düşük seviyede \\
\hline 2 & \multirow{2}{*}{ istatistiksel anlamda süreç kontrol altında ancak her an hata-sorun oluşma olasılığı var. } \\
\hline 3 & \\
\hline 4 & \multirow{3}{*}{$\begin{array}{l}\text { Süreç kotrol altına alınmıştır, ancak tespit edilen değerler kontrol limitlerine-sonırlarına yakın ve } \\
\text { hatanın oluşma-ortaya çıkma olasılığı orta düzeyde. }\end{array}$} \\
\hline 5 & \\
\hline 6 & \\
\hline 7 & \multirow{2}{*}{ Oluşma olasıl Iğı yüksek düzeydedir. } \\
\hline 8 & \\
\hline 9 & Hatanın oluşma-ortaya çıkma ihtimali çok yüksek seviyededir. \\
\hline 10 & Hata her an-her durumda oluşma olasilığı var. \\
\hline
\end{tabular}

Oluşturulan bu tablolar (Tablo 1, Tablo 2 ve Tablo 3) sayesinde ürün bileşenin üretimi sırasında tespit edilen- ortaya çıkabilir hatalara yönelik uzmanlar ve ilgili bölüm çalışanlar ile oluşturulan HTEA ekibi tarafından analiz edilerek hata listesinin çözümüne yönelik önlemler ve faaliyetlerde bulunuldu. Bu faaliyetler ve önlemler listelenip, gerçekleştirildi ve böylece RÖs değerleri düşürüldü, azaltıldı.

\section{Tablo 3: Buzdolabı Bileşenine Ait Hata Saptama Derecelendirme Tablosu}

\begin{tabular}{|c|c|}
\hline 10 & $\begin{array}{l}\text { Hatalı olarak ürünün gönderilmesi, müşteriye gönderilme olasılı̆̆ı çok yüksektir. Ürün kontrol } \\
\text { sürecinden geçirilmez ya da kontrol altına alınabilir değildir. Hata-sorun tespit edilebilir } \\
\text { durumda değildir, görünmez niteliktedir. Üretim-imalat ve montaj süreçlerinde, hatlarında fark } \\
\text { edilemez. }\end{array}$ \\
\hline 9 & $\begin{array}{l}\text { Hata gizli bir özelliktedir ve hatalı şekilde müşteriye teslimi-gönderilmesi yüksek olasılığa } \\
\text { sahiptir. }\end{array}$ \\
\hline 8 & \multirow{2}{*}{ Ürünün hatalı teslimi-gönderlmesi orta düzeyde olaslığa sahiptir. } \\
\hline 7 & \\
\hline 6 & \multirow{3}{*}{ Ürün/hizmetteki hata-sorunun tespit edilebilir özelliktedir. } \\
\hline 5 & \\
\hline 4 & \\
\hline 3 & \multirow{2}{*}{ Ürünün hatalı-sorunlu şekilde teslim edilmesi düşük olasılık düzeyindedir. } \\
\hline 2 & \\
\hline 1 & Hatalı ürün müşteriye teslim edilmez, gitmez. Hata \%99 9 ihtimalle keşfedilebilir. \\
\hline
\end{tabular}

Hataların kendi alt hata bileşenleri olacak şekilde hata ağaç yapısı oluşturuldu. Bu hata modlarının gerçekleşebilme şiddet, olasılık ve hatanın keşfedilebilirlik düzeyleri belirlenip bu değerler HTEA formuna işlendi. Bu işlenen değerlere bağlı olarak Risk Öncelikli Katsayısı (RÖS-RPN) hesaplandı. Bu hesaplanan değerler risk büyüklüğüne göre sıralanıp, RÖS değerinin azaltılmasına yönelik çalışmalarda bulunuldu. 


\section{BULGULAR VE TARTIŞMALAR}

HTEA Analizi işleminden önce sistemde tespit edilen olası mevcut hataların RÖS (RPN) değerlerinin yüksek olduğu görülmüştür. HTEA kuralı gereği yapılan analiz sonucu her bir hataya yönelik alınan tedbir, önlem aksiyonlarına bağlı olarak hatalara yönelik ikinci HTEA ürün, servis, sistem ve süreçlerin geliştirilmesi /iyileştirilmesi faaliyetlerinin ilk aşamalarında kolayca uygulanabilmekte ve faydalı sonuçlar vermektedir. Çalışma her ne kadar üretim yönetimi üzerine kurulsa da diğer eğitim konuları için uygulanabilir bir örnek teşkil etmektedir. Bu tür yöntemlerin üretim yönetiminde kullanulması çalışmanın önemini artmaktadır.

Tablo 4: Buzdolabı Bileşeni için HTEA Analiz Çalışmasının Özetlenmişi

\begin{tabular}{|c|c|c|c|c|}
\hline \multicolumn{5}{|c|}{ ANALİZ DEĞERLENDİRMESINIIN ÖZETLENMISS ŞEKLİ } \\
\hline Süreç & \multicolumn{2}{|c|}{ Hata Türü No } & \multirow{2}{*}{\begin{tabular}{|l|} 
Olası Hata Türü \\
Sıralama ve yerleştirme
\end{tabular}} & \multirow{2}{*}{\begin{tabular}{|c|} 
Tanımlama \\
RÖS değeri 24'den 10'a indirilmiştir.
\end{tabular}} \\
\hline \multirow{8}{*}{$\begin{array}{l}\text { ÖN HAZIRLIK } \\
\text { MONTAJ } \\
\text { AȘAMASI (ÖMA) }\end{array}$} & 1 & ÖMA1 & & \\
\hline & 2 & ÖMA2 & iş istasyon sabitleme- kilitleme & RÖS değeri 36'dan 14'e indirilmiştir. \\
\hline & 3 & ÖMA3 & Bandlama & RÖS değeri 16'den 0'a indirilmiştir. \\
\hline & 4 & ÖMA4 & Yanlış soket işlemi-kulllanımı & RÖS değeri 50'den 30'a indirilmiştir. \\
\hline & 5 & ÖMA5 & Tam sıkımayan kablo bağı & RÖS değeri 50'den 20'a indirilmiştir. \\
\hline & 6 & ÖMAG & Kablo bağlantısının sağlanamaması & RÖS değeri 105'den 30'a indirilmiştir. \\
\hline & 7 & ÖMA7 & $\begin{array}{l}\text { Menteşeye uygunsuz şekilde } \\
\text { soketin ters şekilde takılması }\end{array}$ & RÖS değeri 50'den 20'a indirilmiştir. \\
\hline & 8 & ÖMA8 & Menteşe soket takılmasının unutulması & RÖS değeri 30'den 10'a indirilmiştir. \\
\hline \begin{tabular}{|l|} 
ELEKTRIKSEL \\
AKSAMDA \\
TEST SÜRECi (ETS)
\end{tabular} & 9 & ETS1 & Geri yönde çıkık oluşması & RÖS değeri 98'den 20'a indirilmiştir. \\
\hline \multirow{4}{*}{$\begin{array}{l}\text { DESANT KABLO } \\
\text { KESME } \\
\text { ve TERMINAL } \\
\text { BASMA } \\
\text { SÜRECI (DKTBS) }\end{array}$} & 10 & DKTBS1 & ürün bileşen kablo uzunluğu & $\begin{array}{l}\text { Bu soruna yönelil ilk analizde } 105 \text { olan ROS değeri,yapilan } \\
\text { iyileştirmelerle } 20^{\prime} \text { ye düşürülmüştür. }\end{array}$ \\
\hline & 11 & DKTBS2 & Krimpleme ve izole etme & $\begin{array}{l}\text { RÖS } 108 \text { hesaplanmış, alınan öneyici faaliyetlerle } 14 \text { 'e } \\
\text { indirilmiştir. }\end{array}$ \\
\hline & 12 & DKTBS3 & Yanlış işlemsel kablo kesme & RÖS değeri 98'den 10'a indirilmiştir. \\
\hline & 13 & DKTBS4 & Yanlış istasyon kullanımı & RÖS değeri 50'den 20'a indirilmiştir. \\
\hline \multirow{4}{*}{\begin{tabular}{|l} 
RAST ÇAKMA \\
SÜRECI (RCS) \\
SARIM ISSELMINE \\
YÖNELIK \\
SÜRECI (SIS)
\end{tabular}} & 14 & RCS1 & Sıralama ve yerleştirme & RÖS değeri 36'den 10'a indirilmiştir. \\
\hline & 15 & RCS2 & izole Baskı & RÖS değeri 108'den 14'e indirilmiştir. \\
\hline & 16 & RCS3 & hatalı rast işlemi & RÖS değeri 50'den 30'a indirilmiştir. \\
\hline & 17 & sis1 & Eksik veya fazla malzeme kullanımı & RÖS değeri 36'dan 0'a indirilmiştir. \\
\hline \multirow[b]{2}{*}{$\begin{array}{l}\text { AMBALAJ } \\
\text { AȘAMASI(AS) }\end{array}$} & 18 & $\overline{\text { AS1 }}$ & Eksik veya fazla malzeme kullanımı & RÖS değeri 24'den 0'a indirilmiştir. \\
\hline & 19 & AS2 & kodlama sürecinde yanlışık yapılması & RÖS değeri 20'den $10^{\prime}$ a indirilmiştir. \\
\hline \multirow{2}{*}{$\begin{array}{l}\text { ÇiFTLEME } \\
\text { SÜRECI (CS) }\end{array}$} & 20 & cs1 & Krimpleme ve İzole etme & $\begin{array}{l}\text { RÖS } 108 \text { hesaplanmış, alınan öneyici faaliyetlerle } 10 \text { 'a } \\
\text { indirilmiştir. }\end{array}$ \\
\hline & 21 & $\operatorname{cs} 2$ & Yanlış istasyon kullanımı & RÖS değeri 12'den 0'a indirilmiştir. \\
\hline
\end{tabular}

Çalışmada üretim yönetiminin başarısızığına neden olan hata türleri fonksiyonel olarak gruplanmış ve HTEA yöntemi ile sıralanmıştır. Hata türlerinin tek tek veya grup ağırlıkları dikkate alınarak değerlendirmesi sonucunda ölçme ve değerlendirme aşamasında oluşan hata türlerinin göreceli ağırlıkları öne çıkmıştır (Tablo 4; Şekil 1).

HTEA Çalışması yapılmadan önce Risk Öncelikli Katsayısı ortalama 42 iken, HTEA çalışması yapılıp, olası hataların önlenmesine yönelik yapılan analiz-işlemler sonrası Risk Öncelikli Katsayısı (RÖS) değeri ortalama 5,6 olmuştur ve hata oranı büyük oranda düşüş göstermiştir (Şekil 1). Çalışma sonucunda bir dönemlik iyileşme yüzdesinin teorik olarak \%25,32; fiili olarak \%23,15 olarak gerçekleştiği görülmüştür.

\section{Şekil 1: HTEA Öncesi ve Sonrası Kritik Risk Değerleri (RÖS) Grafiksel Gösterimi}

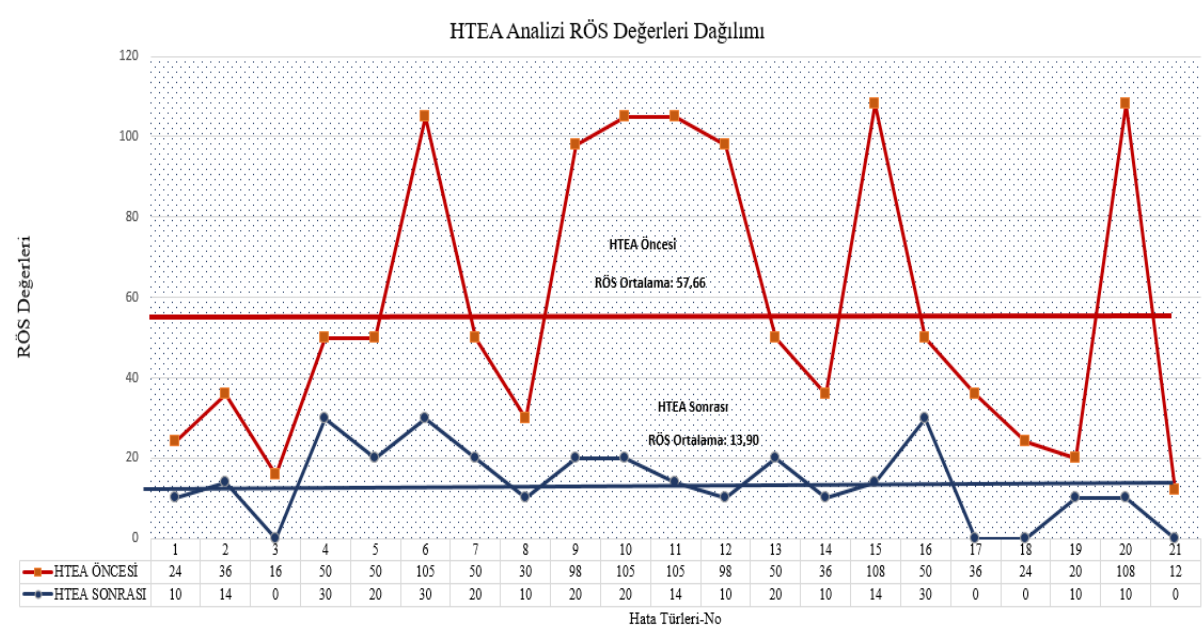


İyileştirme için ayrılacak imkânlar sınırlı olduğu için tüm riskler bir dönem içersinde düşürülmeyebilir. Her dönem yeni belirlenecek önceliklere göre risk önleyici çalışmalar tekrarlanarak sürekli iyileşme sağlanacaktır.

\section{SONUÇ}

Hataların eliminize edilmesine yönelik yapılan HTEA çalışmasında zamana bağlı olarak hatanın etkisinin zamana bağlılı̆ı genel olarak tersi yönde gitmektedir. Zaman kavramını altı evreye ayırdığımızda, ilk üç evrede (Ürün bileşenin sisteme tanımlanması, gelişmesi ve ürünün hazırlanması) ürünün hata etkisini ilk evreden sonraki evrelere geçişte düşüşe geçtiği görülmektedir Üretim, Test ve Kullanım evrelerinde de zamana bağlı olarak hata etkisi giderek azalım yok edilmeye çalışılmıştır (Başlıgil, 1998; Kim ve diğerleri, 2013). Bunun temel nedeni Hataların ürün maliyetine etkisi ise ilerleyen altı evrede kademe kademe yükselişe geçmiştir.

HTEA tablosunda getirilen çözüm önerilerine göre hareket edilerek risk oranlarının düştüğü gözlemlenmiştir. Maliyeti düşürecek değişimlerin yapılmasını sağlayacak düşüncelerin ortaya çıkması amacıyla yapılan ekip çalışmalarında, ekibin kimlerden oluşacağı ve bu kişilerin nasıl bir statüde (devamlı-geçici) çalışacakları ise, o sanayi dalının ve işletmenin özellikleriyle yöneticilerin kararları doğrultusunda çözümlenecek konulardır.

HTEA riskleri önceliklendirmek için birçok endüstride kullanılan önemli bir araçtır. HTEA'nın yetersiz kaldığı noktalarda bu analizi geliştirmek, daha iyi hale getirmek için birçok çalışma yapılmıştır. Bu çalışmalardan biride bulanık mantık ile gri teori yöntemini HTEA ile birleştiren yaklaşımdır (Elliott, 1993; Kim ve diğerleri, 2013). Bu yaklaşımın sonuçları aynı çalışma için geleneksel HTEA ile karşılaştırıldığında, aynı çıkma ihtimali olsada, sonuçların daha kesin olacağı konusunda kafalarda daha az soru işareti bırakmaktadır. Yaklaşımın geleneksel HTEA'ya getirdiği en önemli yenilikler daha esnek, kolay ve hızlı olmasıdır. Zamanın çağımızda çok değerli olduğu herkes tarafından bilinen bir gerçektir ve iş dünyasında hızlı ve kesin olmak aranan, istenen bir olgudur. Yeni yaklaşımın HTEA analizi kullanılan yerlerde bu ihtiyaçlara detaylı ve sağlam bir analizle cevap vermesi beklenmektedir. Bu yaklaşımda, risk faktörleri ve uzmanlar içinde ilişkisel önemlilik ağırlıkları belirlenir. Bu durumda sonuçların daha gerçekçi ve kesin olmasına yardımcı olur. Uzmanların değerlendirmelerde bulanık mantık yaklaşımı sayesinde daha esnek, daha özgür olmaları sağlanır. Bu yaklaşımda uzmanlar birbirinden bağımsız olarak karar verebilirler.

\section{REFERENCES}

Abbie, G., Hauser, J. (1993). The voice of the customer. Marketing Science,12(1), 1-27.

Başlıgil, H. (1997-1998). Yayınlanmamış YBS ders notları. Makine Fakültesi, Y.T.Ü., İstanbul, 2004.

Bellomo, P., Rago, C. M., Spencer, C. M., Wilson, Z. J. (2000). Novel approach to increasing the reliability of accelerator magnets. IEEE Transaction on Applied Superconductivity, 10(1), $284-287$.

Besterfield, D. H., Besterfield-Michna, C., Besterfield, G., Besterfield-Sacre, M. (1999). Total quality management. 2nd Edition, Prentice Hall, New Jersey.

Bilgin, M. (1994). Tasarımda kalite ve FMEA metodu. i̇Ü Fen Bilimleri Enstitüsü Yüksek Lisans Tezi, İstanbul.

Bolat, T. (2000). Toplam kalite yönetimi (Konaklama İşletmelerinde Uygulanması). Beta Basım Yayım Dağıtım A.Ş., İstanbul, 74.

Dizdar, E. N., Kurt, M. (2002). İş güvenliği. Gazi Üniversitesi, Mühendislik Fakültesi Ders Kitabı, 2002 (111), Kale Ofset, Ankara.

Dizdar, E. N. (2000). İnsan hatasi değerlendirilmesi. Teknoloji Dergisi, 3(4), 149-156.

Düzgüner, E. (2002). Ürün geliştirme sürecinde önleyici kalite güvence: FMEA metodu ve bu metodun bir sanayi işletmesindeki uygulaması, yayınlanmamış yüksek lisans tezi. Kayseri: Erciyes Üniversitesi Sosyal Bilimler Enstitüsü

Efil, ì. (2006). Toplam kalite yönetimi. Aktüel yayınları, Şubat 2006.

Eleran, A., Erkan, M., Elitaş, C. (2004). Maliyet muhasebe dersi eğitim sürecinin iyileştirmesinde hata türleri ve etki analizi yönteminin kullanilmasi. Afyon Kocatepe Üniversitesi, İktisadi İdari Bilimler Fakültesi Dergisi, 63-71.

Elliott, J. B. (1998). Risk analysis - two tools you can use to assure product safety and reliability. The Validation Consultant, Booth Scientific Inc.

Engin, O., Kaya, i. (2004). Trafik kazalarinin önlenmesinde hata modu ve etkileri analizi (HMEA) modeli. Polis Bilimleri Dergisi, 6(1-2), Cilt: 6, Sayı: 1-2.

Hough, P. (2000). Failure mode and effect analysis. http://www.wclass.com/fmea1.htm, 10.10.2017 .

Kasa, H., Boran, S. (1993). FMEA ve toplam kalite yönetimi için önemi. YA/EM93 Yöneylem Araştırması Endüstri Mühendisliği 15. Ulusal Kongresi "Küreselleşme Ve Türk Endüstrisi" Bildiriler Kitabı, s. 87.

Kim, K. O., Yang, Y., Zuo, Ming, J. (2013). A new realibility allocationweight for reducing the occurence of severe failure effects. Realibility Engineering and System Security, 117, 81-88.

Klir, G. J., Yuan, B. (1995). Fuzzy sets and fuzzy logic: theory and application, New Jersey: Prentice-Hall, Springer, Berlin.

Milli Prodüktivite Merkezi Yayınları (1998). Verimlilik yönetimi. Uygulamalı El Kitabı, International Labour Office, Ankara. 
Şimşek, M. (2000). Sorularla toplam kalite yönetimi ve kalite güvence sistemleri. 111, Alfa Basım Yayım Ltd. Şti., İstanbul.

Şen, Z. (2001). Bulanik mantik ve modelleme ilkeleri. Bilge Kültür Sanat, İstanbul.

Tamer, B. (2000). Toplam kalite yönetimi. Konaklama İşletmelerinde Uygulanması, Beta Basım Yayım Dağıtım A.S., İstanbul.

Tanyaş, M., Eryürek, Ö. F. (2003). Hata türü ve etkileri analizi yönteminde maliyet odakli yeni bir karar verme yaklaşimi. iтü Dergisi, 2(6):3140.

Pillay, A., Wang, J. (2003). Modified failure mode and effects analysis using approximate reasoning. Reliability Engineering and System Safety, 79(1), 69-85.

Saajedi, A. (2004). Use of advanced in technology in marine risk assessment. Risk Analysis, 20(4), 1011-1033.

Scipioni, A. U. (et al.) (2002). FMEA methodology desing, implementation and integrationwith HACCP system in a food company. Food Control, 13(8): 495-501

Vilko, J. P. P., Hallikas, J. M. (2012). Risk assessment in multimodal supply chains. International Journal of Production Economics, 140, 586595.

Wang, L. X. (1997). A course in fuzzy systems and control. Englewood Cliffs, Willey, New Jersey: Prentice-Hall.

Wang, J., Sii, H. S., Yang, J. B., Pillay, A., Yu, D., Liu, J., Maistralis, E., Saajedi, A. (2004). Use of advanced in technology in marine risk assessment. Risk Analysis, 20(4), 1011-1033.

Wang, Y., Cheng, G., Hu, H., Wu, W. (2012). Development of risk-based maintenance strategy using FMEA for a continuous catalytic reforming plant. Journal of Loss Preventation in the Process Industries 25, 958-965.

Yılmaz, B. S. (2000). Hata türü ve etki analizi. Dokuz Eylül Üniversitesi, Sosyal Bilimler Enstitüsü Dergisi, 2(4), 133-150. iTÜ-TTGV Kalite Ar\&Ge Merkezi, http://www.kageme.itu.edu.tr. 